\title{
Colonic Dieulafoy lesion successfully treated by endoclips: a rare cause of lower gastrointestinal bleeding
}

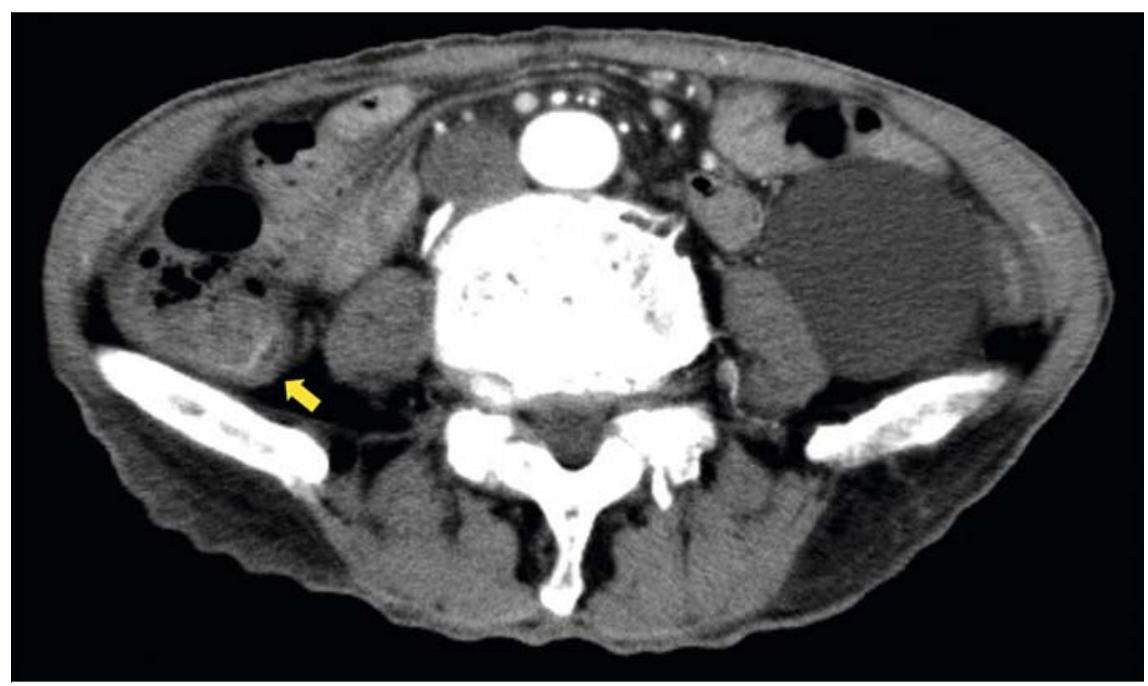

- Fig. 1 Contrast-enhanced computed tomography revealed the presence of extravasation in the ascending colon (yellow arrow).

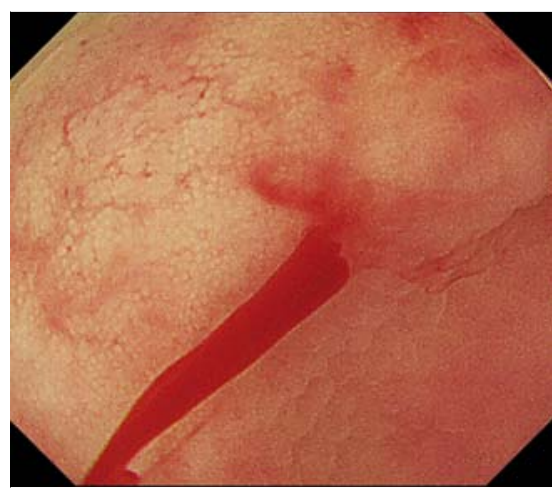

Fig. 3 Colonoscopy showed active bleeding in the ascending colon.

Dieulafoy lesions account for $1 \%-2 \%$ of cases of acute gastrointestinal bleeding. Approximately $71 \%$ of Dieulafoy lesions are detected in the stomach, whereas only $2 \%$ are in the colon $[1,2]$. We encountered a patient with a colonic Dieulafoy lesion that was successfully treated by endoclips.

An 83-year-old man with cirrhosis related to hepatitis $C$ virus presented to our hos-

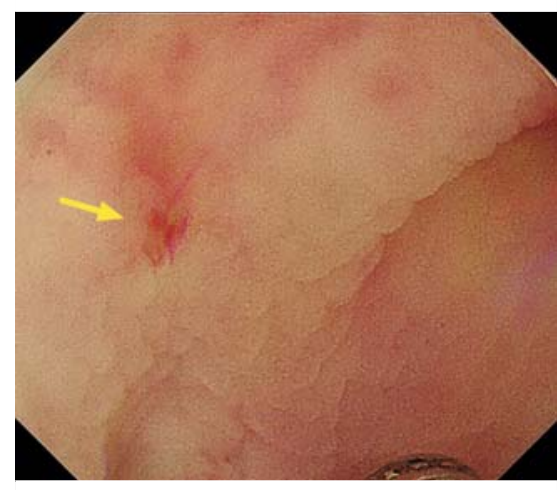

- Fig. 4 The bleeding point had no mucosal abnormality surrounding the lesion (yellow arrow). The lesion was diagnosed as a Dieulafoy lesion.

pital with a 4-day history of hematochezia. At admission, his hemoglobin level was $4.9 \mathrm{~g} / \mathrm{dL}$. Contrast-enhanced computed tomography revealed the presence of extravasation in the ascending colon ( Fig. 1).

Transcatheter arterial embolization (TAE) was performed instead of colonoscopy because the patient's vital signs were unstable. Although hemostasis by TAE

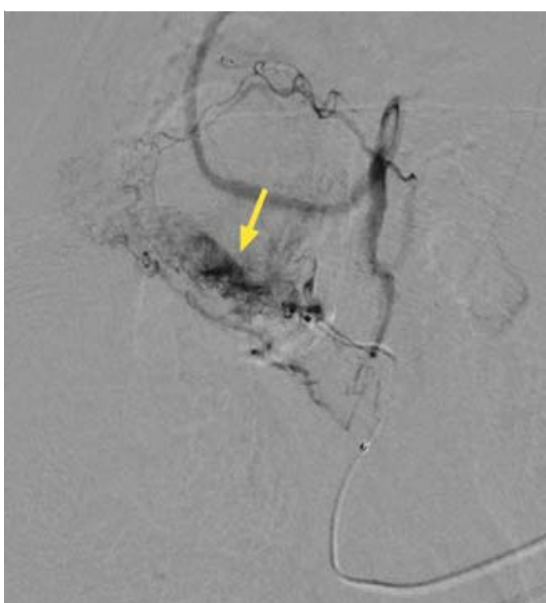

Fig. 2 Abdominal angiography revealed the presence of extravasation in the ascending colon (yellow arrow). Transcatheter arterial embolization (TAE) was performed for bleeding. Bleeding was successfully stopped by TAE.

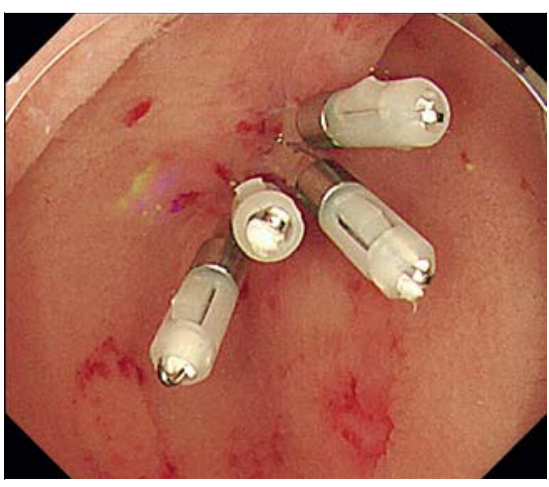

Fig. 5 Bleeding was successfully stopped by endoclips.

was successful ( $>$ Fig.2), he developed hematochezia 4 days after TAE. After bowel preparation with polyethylene glycol, urgent colonoscopy was performed. The presence of fresh blood and clotting was observed throughout the colon, and active bleeding was detected in the ascending colon ( $>$ Fig. 3 ). No mucosal abnormality surrounding the lesion was noted ( $>$ Fig. 4 ). The lesion was diag- 


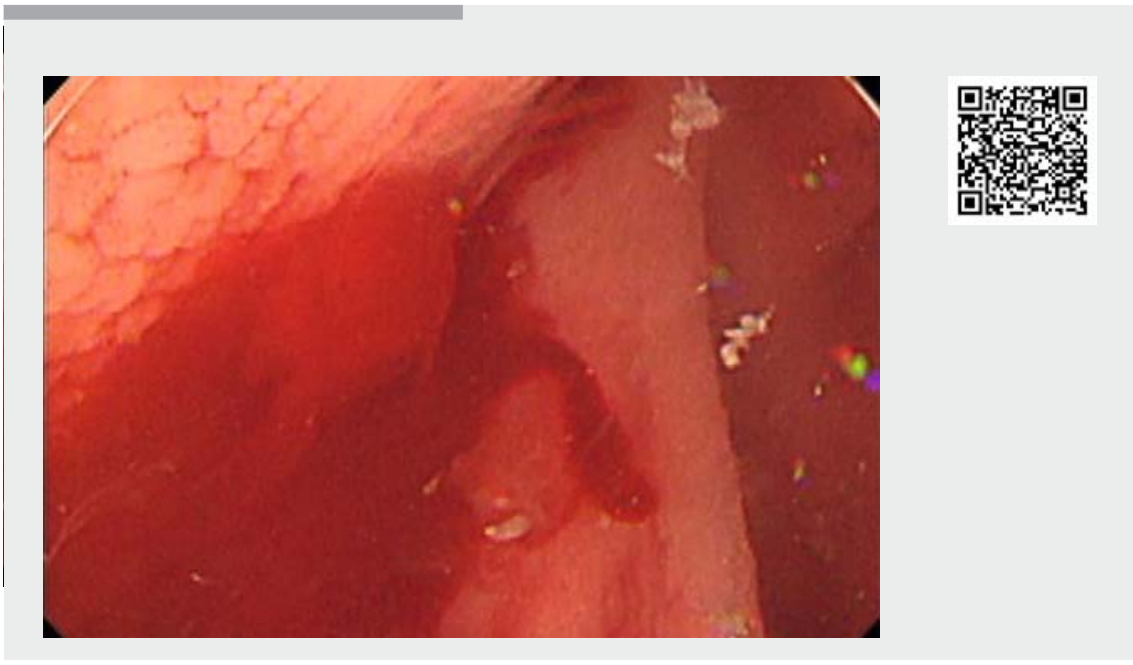

Video 1 Water immersion observation of bleeding from the colonic Dieulafoy lesion, which was successfully treated by endoclips.

nosed as a Dieulafoy lesion and bleeding was stopped by endoclips (\$ Fig.5, - Video 1). Bleeding did not recur after the treatment.

Although colonic Dieulafoy lesions are rare, they need to be included in the differential diagnosis of hematochezia. Repeated endoscopy may be needed to establish a diagnosis because this lesion has almost no mucosal abnormality. Therapeutic endoscopy using endoclips is effective for the treatment of colonic Dieulafoy lesions.

Endoscopy_UCTN_Code_CCL_1AD_2AF

Competing interests
The authors

\section{Takaaki Kishino, Saiyu Tanaka}

Department of Gastroenterology and Hepatology, Center for Digestive and Liver

Diseases, Nara City Hospital, Nara, Japan

\section{Corresponding author}

\section{Takaaki Kishino, MD}

Department of Gastroenterology and Hepatology, Center for Digestive and Liver Disease, Nara City Hospital, 1-50-1

Higashikideracho, Nara 6308305, Japan

Fax: +81-74-2222478

t-kishino@nara-jadecom.jp

\section{References}

[1] Reynolds JK, Mejia VA. Appendiceal Dieulafoy lesion: an unusual cause of massive lower gastrointestinal bleeding. Am Surg 2015; 81: E18-19

[2] Baxter M, Aly EH. Dieulafoy's lesion: current trends in diagnosis and management. Ann R Coll Surg Engl 2010; 92: 548 - 554

\section{Bibliography}

DOI https://doi.org/10.1055/a-0991-7804

Published online: 9.9.2019

Endoscopy 2020; 52: E49-E50

(c) Georg Thieme Verlag KG

Stuttgart · New York

ISSN 0013-726X

\section{ENDOSCOPY E-VIDEOS}

https://eref.thieme.de/e-videos

回题 Endoscopy E-Videos is a free access online section, reporting 靣: on interesting cases and new techniques in gastroenterological endoscopy. All papers include a high quality video and all contributions are freely accessible online.

This section has its own submission website at

https://mc.manuscriptcentral.com/e-videos

None 